\title{
Torsion of cecal appendix. Report of the first Italian case and review of the literature
}

\author{
Salvatore Fabio Chiarenza, Lorenzo Costa, Cosimo Bleve \\ Department of Pediatric Surgery and Pediatric Minimally Invasive Surgery and New Technologies, San Bortolo \\ Hospital, Vicenza, Italy
}

\begin{abstract}
In pediatric patients appendicitis is the most common cause of abdominal pain and surgery. Torsion of vermiform appendix is a rare cause, clinically indistinguishable from appendicitis with usually an intraoperative diagnosis. The first description of vermiform appendix torsion was made by Payne in 1918. Clinical presentation is similar to acute appendicitis. Preoperative investigations play a minimal role. Etiology of this condition is unclear, but is possible to distinguish a primary and a secondary torsion. We report a case of 5-years-old boy who presented with right lower quadrant abdominal pain. His clinical signs, symptoms and investigations mimicked an acute appendicitis. Intraoperatively we found a $720^{\circ}$ appendix torsion on its base with its mesentery rotat-
\end{abstract}

Correspondence: Cosimo Bleve, Department of Pediatric Surgery and Pediatric Minimally Invasive Surgery and New Technologies, San Bortolo Hospital, Viale Ferdinando Rodolfi 37, 36100 Vicenza (VI), Italy.

Tel.: +39.0444 .752642$

E-mail: cosimo.bleve@aulss8.veneto.it

Key words: Laparoscopy; torsion; vermiform appendix; appendicitis.

Conflicts of interest: The authors declare no conflicts of interest.

Availability of data and materials: All data underlying the findings are fully available.

Ethics approval and consent to participate: No ethical committee approval was required for this case report by the Department, because this article does not contain any studies with human participants or animals. Informed consent was obtained from the legal representatives of the patient included in this study.

Consent for publication: Written informed consent was obtained from the legal representatives of the patient for publication of this manuscript and any accompanying images. A copy of the written consent is available for review by the Editor-in-Chief of this Journal.

Received for publication: 10 January 2021

Accepted for publication: 20April 2021.

This work is licensed under a Creative Commons Attribution

NonCommercial 4.0 License (CC BY-NC 4.0).

CCopyright: the Author(s), 2021

Licensee PAGEPress, Italy

La Pediatria Medica e Chirurgica 2021; 43:251

doi:10.4081/pmc.2021.251 ed in counter-clockwise direction. The appendix was gangrenous in appearance. A video-assisted trans-umbilical appendectomy was performed. We describe clinical presentation and management of this rare condition reviewing the literature.

\section{Introduction}

Torsion of vermiform appendix is a rare cause of acute abdominal pain. It was first reported in 1918 by Payne ${ }^{1}$ in the British Journal of Surgery, who described the first case of torsion. Two years later Beevors reported a similar case, this time in Lancet. ${ }^{2}$ This clinic condition is identical in presentation to acute appendicitis. It is seen more frequently in children than in adults and male:female ratio is $4.5: 1{ }^{3}$ No specific age predominates; the range varies from 50 days $^{4}$ to adults ${ }^{5}$ with a 76 years old man as oldest patient. Diagnosis of torsion is invariably made intraoperatively. Primary and secondary torsion of the vermiform appendix have been described. Carcinoid tumor and infestation with parasites such as Schistosoma haematobium may also rarely lead to torsion of the appendix. ${ }^{6,7}$ Rotation of the appendix has been seen in both clockwise and anti-clockwise directions. The appearance of the appendix varies from twisted with minimal inflammation to severely congested and gangrenous or necrotic. A review of the Entrez PubMed literature documented that totally only 59 cases of volvulus of the appendix have been reported of which 25 are in pediatric patients. Our case will be the 26 th and the first Italian case reported.

\section{Case Report}

A five-years-old boy presented to Pediatric Emergencies with 12-hours history of continuous periumbilical abdominal pain associated to 6 episodes of vomiting and a diarrhea. Temperature was $38^{\circ} \mathrm{C}$. At the initial evaluation the abdominal pain was widespread without signs of peritoneal irritation. Lab results showed mild infective signs (WBC: 18700/mm3, CRP: $0.79 \mathrm{mg} / \mathrm{dL}$ ) with ketonuria and acetonemic breath. The patient was reassessed after 18 hours of observation, finding an intensified abdominal pain located in the right lower quadrant area with signs of peritoneal irritation, abdominal wall defense/muscular rigidity and positive Blumberg's sign. A complete blood count repeated showed leukocytosis $(16,400 \mathrm{wbc} / \mathrm{mm} 3$ with $84,7 \%$ neutrophils). Abdominal ultrasound showed thin fluid film contouring intestinal loops in both small pelvis and right iliac fossa where they appear distended by liquid. In right iliac fossa also, was described a liquid flap with 
a maximum thickness of $8 \mathrm{~mm}$ and a rounded $12 \mathrm{~mm}$ hyperechoic area suspected for collection. The appendix was not visualized. An emergency operation was performed under the diagnosis of acute appendicitis. The operation was performed using the conventional video-assisted trans-umbilical laparoscopic technique. Laparoscopy showed inflammatory fluid in pelvic cavity and an indurated area in the right iliac fossa/parietocolic spaces. Lysis of adhesions between omentum, small intestine, and cecum was performed, identifying a gangrenous appendix, 6-7 cm in length and $1 \mathrm{~cm}$ in diameter, twisted two times $\left(720^{\circ}\right.$, Figure 1$)$ in counterclockwise at the point of $1.5 \mathrm{~cm}$ distal to its base and attached to the abdominal wall of the right parietocolic spaces (Figure 2). The torsion leads to a congestion of appendix vessels wall and venous thrombosis (Figure $3 \mathrm{a}$ and $3 \mathrm{~b}$ ). The appendix presented a narrow appendicular mesentery and a movable cecum without fixation. A video-assisted Trans-Umbilical Appendectomy (TULAA) was performed, exteriorizing the appendix and the cecum through the umbilical scar. Operative time was 50 minutes. Feeding was start- ed on 1 st postoperative; the boy was discharged on second day. Histological examination of appendix showed transmural inflammation and necrosis with fibrino-leucocytic infarction.

\section{Discussion}

Torsion of the vermiform appendix is a rare cause of acute abdominal pain. It occurs as a result of twisting of the appendix along its longitudinal axis. The site of torsion is usually, at least 1 centimeter from the base of the appendix and is less frequent at the base. Torsion degree is usually between $180-1080^{\circ}$ while the direction of rotation is variable, but counter-clockwise is more frequent. We are unable to identify any association between the degree of rotation and etiology or presentation in view of the relatively small sample size. All that is known is that a rotation of 120 degrees is enough to compromise vascular supply in some patients. Torsion

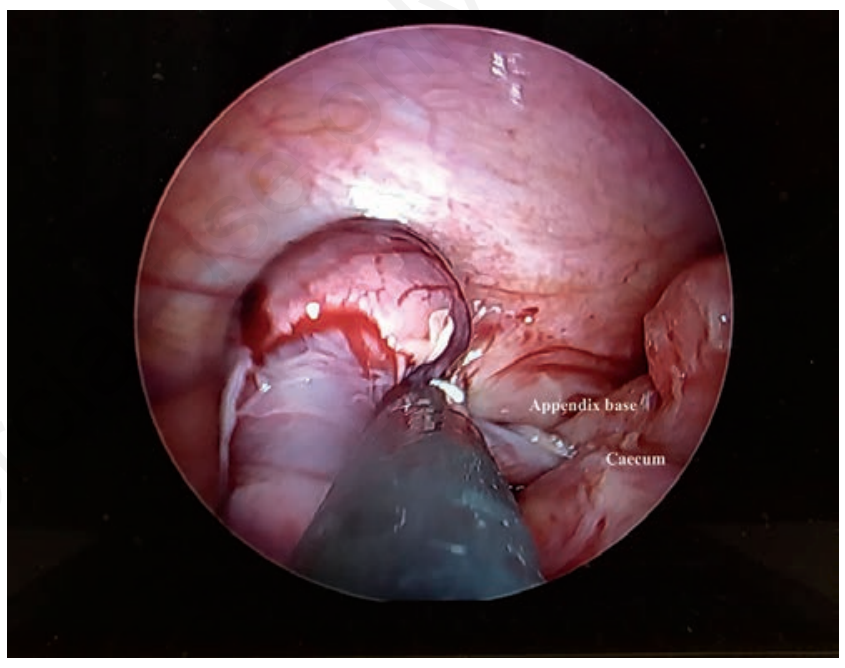

Figure 2. Normal appendix base $1.5 \mathrm{~cm}$ distal to the site of torsion.

Figure 1. Twisted appendix with a torsion of $720^{\circ}$ in counterclockwise direction.

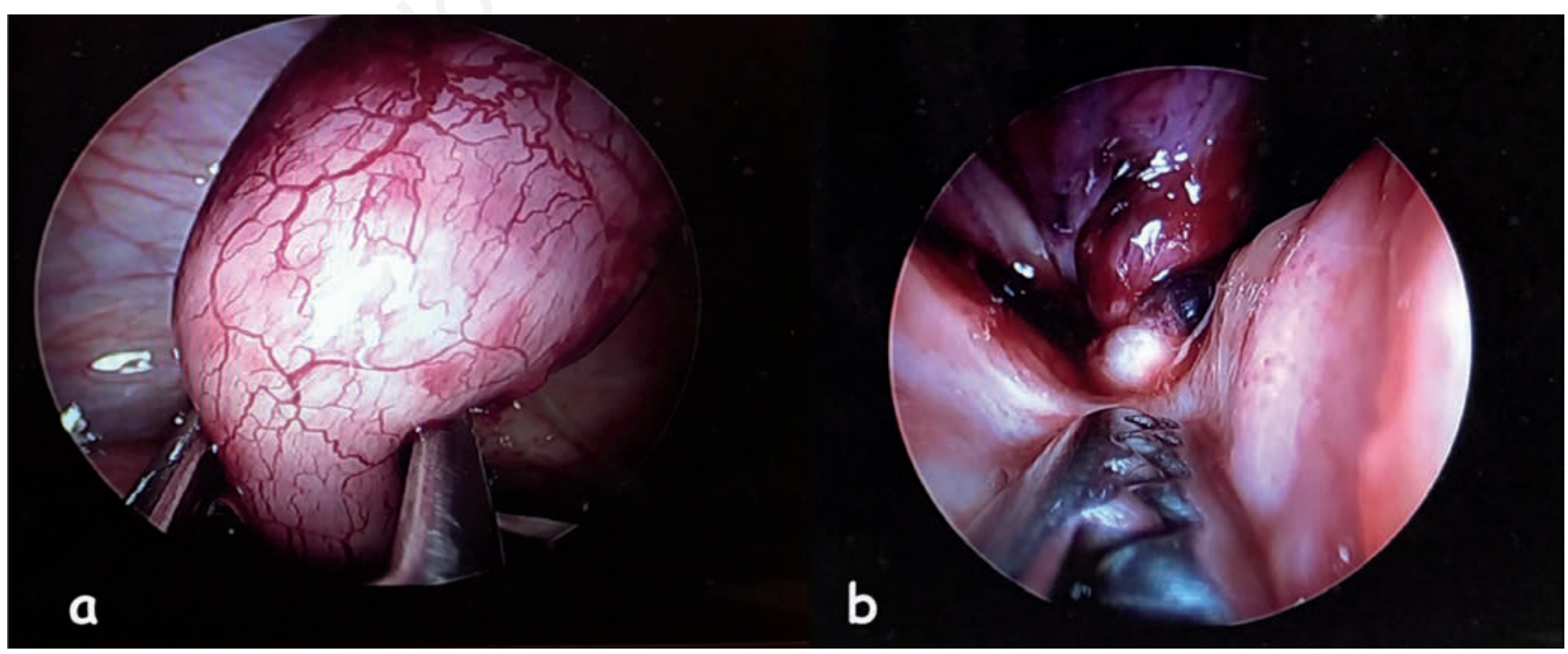

Figure 3. a) Vessel wall appendix congestion; b) Particular of torsion with venous thrombosis. 
leads to lumen obstruction compromising the lymphatic drainage and venous return obstructing the arterial supply, resulting in strangulation, hemorrhagic infarct and consequent inflammatory response, which leads clinically to an acute abdomen. From the first description by Payne in $1918,{ }^{1}$ by a review of the Literature we found other papers reporting a description of this condition. Montes-Tapia et al. in 20096 reported that 15 pediatric patients were describe previously, while in 2012 Dimitriadis et al. ${ }^{8}$ in reviewing the English literature described a total of 30 cases reported in adult populations including their case and 16 cases in pediatric patients. Adi et al. ${ }^{9}$ in 2014 wrote that torsion of appendix has been reported 30 times in the last century, half of which were in pediatric patients; Ioannis et al. 10 in 2017 cited that 17 cases have been reported in children while Endo et al. in 2020 described 22 pediatric cases including his one. ${ }^{11}$ We reported our case, the first Italian, and the 26th in pediatric population reported by English literature. Mean age in this pediatric cohort of 26 children is 6.5 years and males are predominant $(84,6 \%)$; the appendix torsion varies from 270-1080 degrees. Among the predisposing conditions: i) a duplicate appendix was found in one patient, ii) an absent mesoappendix (which was proposed as a predisposing contributory factor) in three; iii) a narrow appendicular mesentery and movable cecum in two patients including our one. Vomiting is present in almost all patients as a presenting symptom, fever in 20 (about 77\%). Length of the appendix is reported in 16 patients (approximately $73 \%$ of cases) varying from 5 to $15 \mathrm{~cm}$. Only one among the reported etiology was a secondary torsion (simple mucocele); in the remaining cases was a primary torsion. The predominant preoperative diagnosis was acute appendicitis (peritonitis-perforated appendicitis with periappendicular abscess) (Table 1). Is not possible to identify any association between the rotation, its degree and clinical presentation. Clinical presentation is similar to acute appendicitis. The two conditions remain clinically indistinguishable, and their management should be the same. ${ }^{31}$ In pediatric cases after admission, observation usually is adopted followed by emergency operations because symptoms did not improve. ${ }^{11}$ Etiology of appendix torsion is not known. It is postulated that various pathologies might be responsible. Primary and secondary torsion of vermiform appendix have been described. Primary torsion seems to happen more often in children while secondary torsion is noticed mainly in adults. ${ }^{10-32}$ In a review of 33 adults with appendiceal torsion, reported during 1918-2018, only one had an associated congenital anomaly "cecal malposition". $11,30,33$ In primary torsion is hypothesized that the axial rotation is due to different possible cause: i) to abnormalities of the mesentery, such as a narrow base, as occurred in our case, ii) to the

Table 1. Cases of appendiceal torsion reported in the English literature (UD: undetermined).

\begin{tabular}{|c|c|c|c|c|c|c|c|c|c|c|}
\hline $\begin{array}{l}\mathrm{N}^{\circ} \\
\text { cas }\end{array}$ & $\begin{array}{l}\text { Author } \\
\text { es }\end{array}$ & Year & Age & Sex & Degree & Lenght & $\begin{array}{l}\text { Etiology } \\
\text { of torsion }\end{array}$ & $\begin{array}{l}\text { Fever } \\
(\mathrm{cm})\end{array}$ & $\begin{array}{l}\text { Nausea/ } \\
\text { vomiting }\end{array}$ & $\begin{array}{l}\text { Preoperative } \\
\text { diagnosis }\end{array}$ \\
\hline $\begin{array}{l}1 \\
2\end{array}$ & Carter $^{12}$ & 1959 & $\begin{array}{c}8 \\
16\end{array}$ & $\begin{array}{l}\mathrm{F} \\
\mathrm{M}\end{array}$ & $\begin{array}{l}>360^{\circ} \\
>360^{\circ}\end{array}$ & $\begin{array}{l}- \\
-\end{array}$ & $\begin{array}{l}\text { UD } \\
\text { UD }\end{array}$ & $\begin{array}{l}38.3^{\circ} \\
37.4^{\circ}\end{array}$ & $\begin{array}{l}\text { Vomiting } \\
\text { Nausea }\end{array}$ & $\begin{array}{l}\text { UD } \\
\text { UD }\end{array}$ \\
\hline 3 & Chan ${ }^{13}$ & 1965 & 18 & $\mathrm{~F}$ & $1260^{\circ}$ & 10 & Simple mucocele & 37.3 & No & Acute appendicitis \\
\hline 4 & Ghent ${ }^{14}$ & 1966 & 12 & M & $360^{\circ}$ & 7 & Primary & $37.6^{\circ}$ & Nausea & UD \\
\hline 5 & Finch $^{15}$ & 1974 & 12 & M & $270^{\circ}$ & - & UD & $37.2^{\circ}$ & Vomiting & UD \\
\hline 6 & Willan ${ }^{16}$ & 1983 & 4 & M & $720^{\circ}$ & 7 & UD & $37.3^{\circ}$ & Vomiting & Acute appendicitis \\
\hline $\begin{array}{l}7 \\
8 \\
9\end{array}$ & Dewan ${ }^{17}$ & 1986 & $\begin{array}{c}3 \\
6 \\
16\end{array}$ & $\begin{array}{l}\mathrm{M} \\
\mathrm{F} \\
\mathrm{M}\end{array}$ & $\begin{array}{c}720^{\circ} \\
1080^{\circ} \\
-\end{array}$ & $\begin{array}{l}7 \\
7 \\
-\end{array}$ & $\begin{array}{l}\text { UD } \\
\text { UD } \\
\text { UD }\end{array}$ & $\begin{array}{c}37.9^{\circ} \\
37.4^{\circ} \\
\text { No }\end{array}$ & $\begin{array}{c}\text { Vomiting } \\
\text { Vomiting } \\
\text { UD }\end{array}$ & $\begin{array}{l}\text { UD } \\
\text { UD } \\
\text { UD }\end{array}$ \\
\hline 10 & Waters et al 18 & 1986 & 3 & M & $720^{\circ}$ & - & UD & $38.9^{\circ}$ & Vomiting & Exploratory lap \\
\hline 11 & Yeung et al. ${ }^{19}$ & 1991 & 50 days & M & - & - & UD & High fever & - & Generalised peritonitis \\
\hline 12 & Merret et al. ${ }^{20}$ & 1992 & 14 & M & $720^{\circ}$ & 14 & Normal Appendix & $37.5^{\circ}$ & Vomiting & Acute appendicitis \\
\hline 13 & Gilchrist ${ }^{21}$ & 1995 & 6 & M & $360^{\circ}$ & 9 & Long narrow mesoappendix & $37.2^{\circ}$ & Vomiting & UD \\
\hline 14 & Val-Bernal et al. ${ }^{22}$ & 1996 & 6 & M & $>360^{\circ}$ & 13.5 & Primary & $37.5^{\circ}$ & Vomiting & Acute appendicitis \\
\hline 15 & Uroz-Tristan et al. 23 & 1998 & 5 & M & $360^{\circ}$ & 15 & Absent mesoappendix & No & Vomiting & Torsion or mucocele \\
\hline 16 & Oguzkurt et al..$^{24}$ & 2004 & 2 & M & $270^{\circ}$ & $10 \mathrm{D}$ & uplicated colon and appendix & $38^{\circ}$ & Vomiting & UD \\
\hline 17 & Gopal Ket al. ${ }^{25}$ & 2005 & 9 & M & $720^{\circ}$ & 5 & Primary & No & Vomiting & Acute appendectomy \\
\hline 18 & Sarin ${ }^{26}$ & 2006 & 9 & M & $270^{\circ}$ & 8 & Normal appendix & $37.7^{\circ}$ & Vomiting & UD \\
\hline 19 & Montes Tapia ${ }^{6}$ & 2009 & 3 & M & $1080^{\circ}$ & - & $\begin{array}{c}\text { Narrow appendicular } \\
\text { nesentery and movable cecum }\end{array}$ & UD & Vomiting & Acute appendicitis \\
\hline 20 & Lena Perger27 & 2011 & $11 \mathrm{w}$ & $\mathrm{F}$ & $360^{\circ}$ & - & UD & Low-grade fever & Emesis & Acute appendicitis \\
\hline 21 & D'Souza ${ }^{28}$ & 2011 & 2 & M & - & 6.5 & UD & $38.3^{\circ}$ & Vomiting & Acute appendicitis \\
\hline 22 & Hirpara29 & 2018 & 2 & M & $720^{\circ}$ & 7.5 & Lymphoid hyperplasia & Low-grade fever & Emesis & $\begin{array}{c}\text { Acute appendicitis } \\
\text { or Meckel's diverticulitis }\end{array}$ \\
\hline 23 & Endo et al. 11 & 2019 & 4 & M & $720^{\circ}$ & 8 & Primary & 37.2 & Vomiting & Acute appendicitis \\
\hline $\begin{array}{l}24 \\
25\end{array}$ & Samuk30 & 2020 & $\begin{array}{l}40 \text { months } \\
23 \text { months }\end{array}$ & $\begin{array}{l}\mathrm{M} \\
\mathrm{M}\end{array}$ & $1080^{\circ}$ & - & $\begin{array}{l}\text { UD } \\
\text { UD }\end{array}$ & $\begin{array}{l}\text { UD } \\
\text { UD }\end{array}$ & $\begin{array}{l}\text { Vomiting } \\
\text { Vomiting }\end{array}$ & $\begin{array}{c}\text { Acute appendicitis } \\
\text { Perforated appendicitis } \\
\text { with periappendicular } \\
\text { abscess }\end{array}$ \\
\hline 26 & Present study & 2021 & 5 & M & $720^{\circ}$ & 6-7 & $\begin{array}{c}\text { Narrow appendicular } \\
\text { nesentery and movable cecum }\end{array}$ & $38^{\circ}$ & Vomiting & $\begin{array}{c}\text { Acute } \\
\text { appendicitis }\end{array}$ \\
\hline
\end{tabular}


absence of azygotic folds that normally laterally fix the appendix, iii) to cecal malposition, iv) to abnormal peristaltic movements and v) to vigorous physical exercise. Secondary torsion of appendix is rarest. It occurs in association with a mucocele, bilharzia, fecaliths, intussusception, mesoappendiceal lipoma, cystadenoma, duplication of appendix; but also, adhesions and inflammation causing distention could favorite instability and a tendency to twist.32,34,13 Carcinoid tumors and infestation with parasites such as Schistosoma haematobium may also rarely lead to torsion of the appendix. The features that are commonly associated with torsion of appendix include long appendix and pelvic position of the appendix. An abnormally long appendix was described in most studies with a mean length of $9.6 \mathrm{~cm} .{ }^{8}$ Clinical presentation of vermiform appendix volvulus may be similar to an appendicular abscess/acute appendicitis with or without perforation both on physical examination and imaging. ${ }^{2} 8$ In our case ultrasound showed in the right iliac fossa, a presence of a liquid flap, an hyperechoic area suspected for collection (abscess). Imaging does not play major role in these cases. Abdominal ultrasound has been used as first step imaging study to find the vermiform appendix, in the differential diagnosis of the most frequent causes of pain in the right iliac fossa, but is difficult to describe an appendicular torsion. In our case, the appendix was not found. In literature, there're no data reported about US-imagine criteria of appendicular torsion. Only Uroz-Tristan and co-workers reported a case where US examination rendered torsion beside the inflammation of the appendix, ${ }^{23}$ while Hamada et al. ${ }^{35}$ reported that target-sign like appearance was a useful finding in identifying appendiceal torsion. Treatment is simple appendicectomy if diagnosis is prompt and intervention is earlier before complications by the conventional approach or by laparoscopy.

\section{Conclusions}

In children, the appendix can be source of rare pathological entities that can present as surgical emergencies. Torsion of the vermiform appendix is a very rare disease and difficult to differentiate from appendicitis. The short interval between arrival at the Emergencies Department and the timing of surgery reflects the acuteness of clinical presentation and the need for an emergent operation. Nowadays thanks to minimal invasive surgery, laparoscopy can prove the torsion and the twisted appendix can be removed laparoscopically or by video-assisted trans-umbilical laparoscopy as in our case. There is a consensus that the appendicular volvulus cannot be distinguished from acute appendicitis preoperatively. However, is possible to conclude that laboratory tests (lack of characteristic signs of inflammation), the advancements in US imaging and the rapidly growing use of diagnostic (preoperative) laparoscopy might modify this general view.

\section{References}

1. Payne J. A case of torsion of the appendix. Br J Surg 1918;6:327.

2. Beevors EC. Torsion of the appendix. Lancet 1920;195:597-8.

3. Somogyi R, Kutasy B, Csízy I, et al. Torsion of the vermiform appendix. Report of 2 cases. Journal of Paed Surg Specialties 2009 3:46-7.

4. Yeung CK, Saing H. Primary torsion of the vermiform appendix in a 50-day-old infant. Pediatr Surg Int 1991;6:223-4.
5. Tzilinis A, Vahedi MH, Wittenborn WS. Appendiceal torsion in an adult: Case report and review of the literature. Curr Surg 2002;59:410-1.

6. Montes-Tapia F, Quiroga-Garza A, Abrego-Moya V. Primary torsion of the vermiform appendix and undescended cecum treated by video-assisted transumbilical appendectomy. J Laparoendosc Adv Surg Tech A 2009;19:839-41.

7. Kitagawa M, Kotani T, Yamano T, Tsurudome H, et al. Secondary torsion of vermiform appendix with mucinous cystadenoma. Case Rep Gastroenterol 2007;1:32-7.

8. Dimitriadis PA, Makar RR, Randall JK, Ramus J. Appendiceal torsion associated with undescended caecum: a case report and review of the literature. BMJ Case Reports 2012;2012:bcr2012006932.

9. Adi MY, Bader M, Jester I. Torsion of the vermiform appendix: A rare intraoperative finding. Int $\mathrm{J}$ Case Rep Images 2014;5:299-301.

10. Ioannis V, Irene P, Vasileios S, Dimitrios S. Laparoscopic treatment of vermiform appendix torsion. APSP J Case Rep 2017;8:36.

11. Endo K, Sato M, Saga K, et al. Torsion of vermiform appendix: case report and review of the literature. Surg Case Rep 2020;6:6.

12. Carter AE. Torsion of the Appendix. Postgrad Med J. 1959;35:671-2.

13. Chan KP. Volvulus complicating mucocele of the appendix. $\mathrm{Br}$ J Surg 1965;52:713-4-

14. Ghent WR, Carnovale BV. Primary volvulus of the appendix. Can Med Assoc J 1966;95:926-7.

15. Finch DR. Torsion of the appendix. Br J Clin Pract 1974;28:391-2.

16. Willan PT, Wickham MH. Torsion of the appendix. Ir J Med Sci 1983;152:168.

17. Dewan PA, Woodward A. Torsion of the vermiform appendix. J Pediatr Surg 1986;21:379-80.

18. Waters DJ, Wilson BE, Salow W. Acute appendiceal torsion a rare surgical entity: report of a case and review of the literature. Am Osteopath 1986;86:224-5.

19. Yeung CK, Saing H. Primary torsion of the vermiform appendix in a 50-day-old infant. Pediatr Surg Int 1991;6:223-4.

20. Merrett ND, Lubowski DZ, King DW. Torsion of the vermiform appendix a case report and review of literature. Aust N Z J Surg 1992;62:981-3.

21. Gilchrist BF. Torsion of the appendix. J Pediatr Surg 1995;30:901-2.

22. Val-Bernal JF, González-Vela C, Garijo MF. Primary acute torsion of the vermiform appendix. Pediatr Pathol Lab Med 1996;16:655-61.

23. Uroz-Tristan J, Garcia-Urguelles J, Poenare D, et al. Torsion of vermiform appendix: value of ultrasonographic finding. Eur J Pediatr Surg 1988;8:376-7.

24. Oğuzkurt P, Oğuzkurt L, Kayaselcuk F, Öz S. An unusual cause of acute abdomen: torsion of colonic duplication over a duplicated appendix. Pediatr Surg Int 2004;20:722-3.

25. Gopal K, Kumar S, Grewal H. Torsion of the vermiform appendix. J Pediatr Surg 2005;40:446-7.

26. Sarin YK, Pathak D. Torsion of vermiform appendix. Indian Pediatr 2006;43:266-7.

27. Perger L, Muensterer OJ. Laparoscopic appendectomy for torsed appendix presenting as an acute abdomen in an infant female. JSLS 2011;15:565-7.

28. D'Souza GF, Abdessalam S. Volvulus of the appendix: a case report. J Pediatr Surg 2011;46:E43-4.

29. Hirpara DH, Azzie G. Acute torsion and ischemia of the appen- 
dix in a young child. J Pediatr Surg Case Rep 2018;31:77-9.

30. Samuk I, Dlugy E, Seguier-Lipszyc E, et al. Not only appendicitis: rare appendix disorders manifesting as surgical emergencies in children. Eur J Ped 2021;180:407-13.

31. Darbyshire D, Sutton PA, Kosai NR, Varghese J. Torsion of the vermiform appendix - A review of the literature. West London Med J 2011;3:14-8.

32. Wani I, Kitagawa M, Rather M, et al. Torsion of vermiform appendix with fecalith: a case report. Cases J 2008;1:20.
33. Wan Hassan WA, Tay YK, Ghadiri M. Torsion of the vermiform appendix: a case report and review of literature. Am J Case Rep 2018;28:365-8.

34. Suggala S, Gopi E, Sreejayan M. Torsion of vermiform appendix: a case report. Internet J Surg 2008;17:4-7.

35. Hamada T, Kosaka K, Shigeoka N, et al. Torsion of the appendix secondary to appendiceal mucocele: gray scale and contrast-enhanced sonographic findings. J Ultrasound Med 2007;26:111-5. 